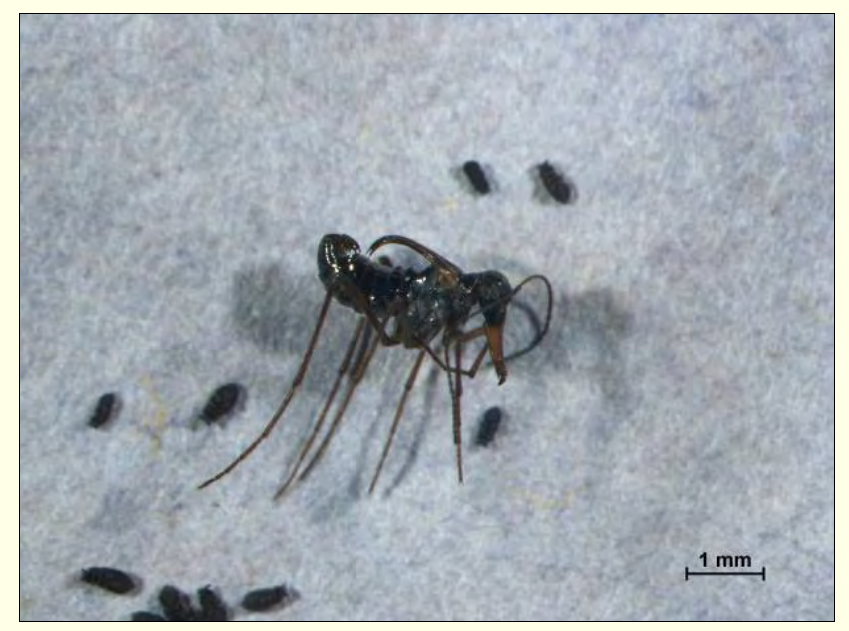

Slika 5. Snežna bolha in skakači.

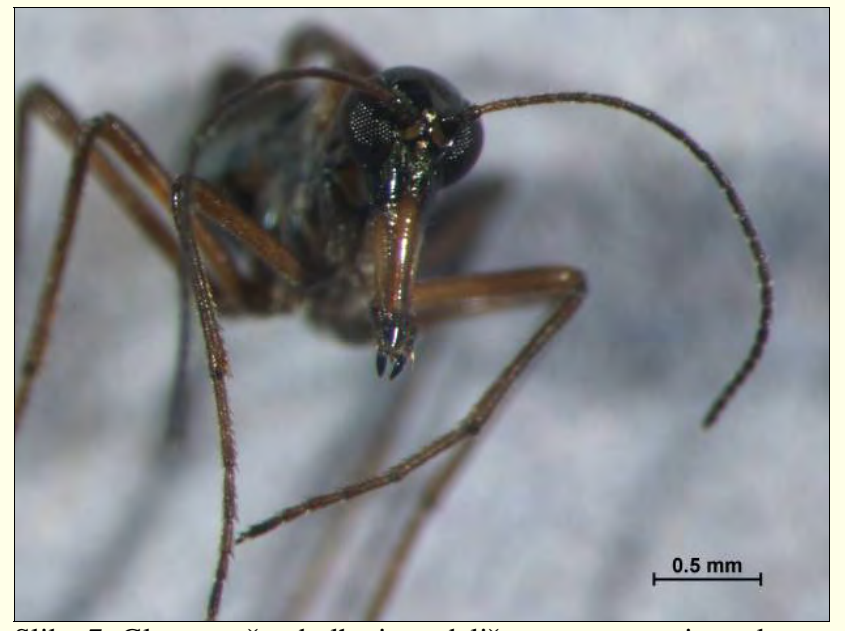

Slika 7. Glava snežne bolhe je podaljšana v rostrum in na koncu je grizalo.

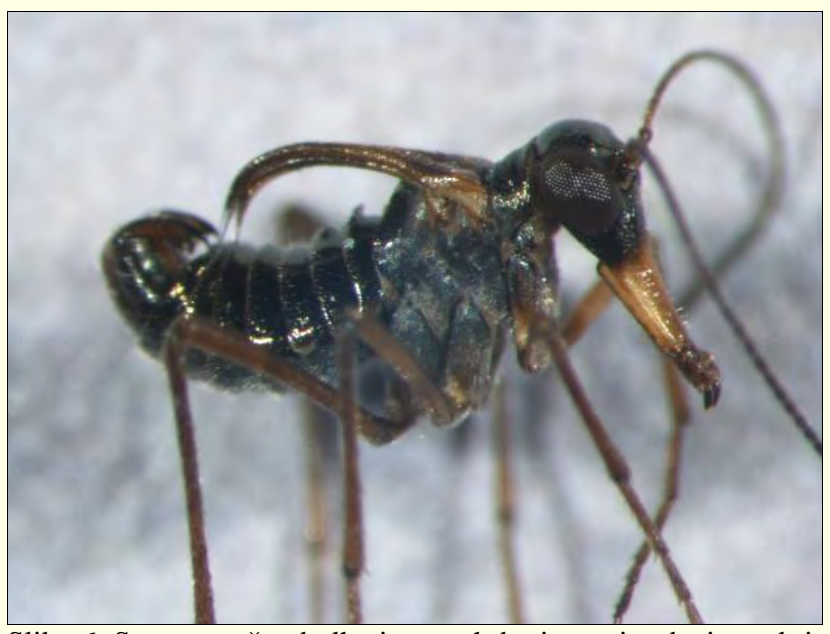

Slika 6. Samec snežne bolhe ima na hrbtni strani reducirana krila.

\title{
Tujerodni podlubnik Xylosandrus germanus se širi v gozdovih Sloveni- je
}

\section{Maja JURC $^{1 *}$, Zoran Zavrtanik², Matej Reščič ${ }^{3}$}

Podlubnik Xylosandrus germanus (Blandfort, 1894) (Curculionidae: Scolytinae) dolbe rove v lesu iglavcev in listavcev. $\mathrm{V}$ rove zanaša različne glive, ki po eni strani povzročijo trohnenje lesa, po drugi strani pa predstavljajo, skupaj s trohnečim lesom, ustrezno hrano zarodu (zato je skupno ime za te glive "ambrozijske" glive). Običajno ga uvrščamo med sekundarne škodljive organizme (ŠO), včasih pa se pojavi na zdravem drevju in ga poškoduje. Takrat ga imenujemo primarni ŠO.

Gostiteljske drevesne vrste: pojavlja se na več kot 200 drevesnih vrstah kot so npr. breze, bukev, bresti, javori, oreh, hrasti, platane, tulipanovec, vrbe, jablane, jeseni, lipe, koprivovci, pravi kostanj, cedre, bori, brini, smreke, jelke, čuge, octovec, gaber, kosteničevje, ebenovec, sleč, divji kostanj, in še na številnih drugih drevesnih vrstah. V Evropi so poročali o napadih na nas- lednjih drevesnih vrstah: Quercus spp., Juglans regia, Picea abies, Pinus sylvestris, Abies alba. Naseli se lahko na popolnoma zdrava ali že oslabljena drevesa in povzroča njihovo sušenje. S prenosom ambrozijskih gliv v gostiteljska drevesa povzroča okužbe lesa in tako še hitreje razvrednoti les (slika 7).

Xylosandrus germanus izvira iz vzhodne Azije (Japonska, Vietnam, Kitajska). Leta 1932 je bil zanesen v ZDA ter leta 1994 v Kanado. V Evropi so ga odkrili leta 1952 v Nemčiji, leta 1994 v Švici in Belgiji, iz leta 2001 je poročilo o najdbi v Rusiji. V Belgiji se je v enem letu razširil že na 4.000 ha navadne bukve in je začel povzročati poškodbe. Leta 2005 so ga prvič našli na Madžarskem v območju Baranya.

Najdišča v Sloveniji so na Primorskem, Gorenjskem, Notranjskem in v okolici Ljubljane, po dostopnih podatkih je lokacij 6 (slika 1). Prvič je bil najden 
26. 4. 2000 v bližini Solkana pri Novi Gorici na evropskem pravem kostanju (Castanea sativa Mill.) (podatek Prirodoslovnega muzeja Slovenije, Ljubljana). V okviru monitoringa vektorjev borove ogorčice (2007-2009) je bil dne 16. 7. 2008 najden na lokacijah Brdo pri Kranju ter Bitnje pri Kranju v sestoju rdečega bora $\mathrm{v}$ pasteh z atraktanti. 31. 5. 2009 smo X. germanus našli v sestoju navadne jelke (Abies alba Mill.) v bližini avtocestne postaje Log pri vasi Bevke, v naravnem rezervatu Mali plac. Maja 2010 se je pojavil na mlajšem drevju evropskega pravega kostanja na lokaciji Ajševica pri Novi Gorici kjer je povzročil sušenje drevja (slika 2). V okviru monitoringa vektorjev borove ogorčice smo v času 21. 6. do 8. 9. 2010 na lokaciji Podpeč (Krim) s pomočjo pasti, ki jih standardno uporabljamo za spremljanje kozličkov, ugotovili povečano populacijo $X$. germanus v sestojih navadne jelke. Povečano število lokacij nahajališč $X$. germanus v zadnjih letih, povečano število ujetih hroščkov v pasteh in njegov pojav kot primarni ŠO pomeni, da se je ta tujerodni podlubnik uspešno naselil, širi se po Sloveniji in morda bo začel povzročati gospodarske škode tudi pri nas.

\section{Napad na lokaciji Mali plac}

Podlubnik se je pojavil na dveh starejših in na enem mlajšem deblu navadne jelke (slika 3). Črvino v obliki "palčk", ki so bile dolge od 0,5 do $22 \mathrm{~mm}$ smo opazili 31. 5. 2009 v predelu od dnišča debla do prsne višine. $\mathrm{V}$ naslednjih dneh je črvina izginila, ker jo je spral dež (slika 4).

Dne 9. 6. 2009 so gozdarji posekali deblo napadene jelke in na njej smo začeli z raziskavo ekologije in asociacijskih gliv tega podlubnika. Odrasli hroščki se pojavijo $\mathrm{v}$ tretjem tednu maja, rojijo konec maja do sredine junija. Napad odkrijemo spomladi po majhnih, nekaj centimetrov dolgih palčkah iz svetle črvine (izgledajo kot tanki “špageti”), ki jih oblikujejo samice pri dolbenju hodnikov. Samice dolbejo rove, ki so vzporedni z letnicami 0,8 do $20 \mathrm{~mm}$ globoko v lesu. "Palčke" vidimo na skorji do prvega deževja ali moč- nejšega vetra, ko se črvina "palčk” drobi in odpade ali jo odplavi dež. $\mathrm{V}$ materinske rove samica na svoji površini, z iztrebki in $\mathrm{v}$ posebnih organih (mikangijih) zanaša "ambrozijske" glive, najpogosteje iz rodu Fusarium. Z glivami in razkrajajočim se lesom se prehranjujejo ličinke podlubnika. Samci so svetlo rjave barve, dolgi so 1,0 do $1,8 \mathrm{~mm}$, samice so svetleče črne barve in so dolge od 2,0 do 2,5 mm (slika 5, slika 6).

$\mathrm{V}$ ujmah podrto drevje je ustrezen habitat za naselitev in razvoj $X$. germanus. $Z$ njegovo naselitvijo se še dodatno povečajo ekonomske škode, ki so nastale zaradi abiotske motnje. Beležijo tudi pogostejše pojave te vrste v sestojih, ki so prizadeti zaradi sušnega stresa. Trenutni status $X$. germanus v Sloveniji je, da se pojavlja lokalno, v omejenih populacijah in se širi.

\section{Viri}

Gill S., Blessington T., Dutky E. 1998. From Maryland Central Maryland Research and Education Center Ellicott City, Maryland, http://www.agnr.umd.edu/ipmnet/may2898.htm

Henin J., Versteirt M. 2004. Abundance and distribution of Xylosandrus germanus (Blandford 1894) (Coleoptera, Scolytidae) in Belgium: new observations and an attempt to outline its range. $\mathrm{J}$ Pest Sci, 77: 57-63

Lakatos F., Kajimura H. 2007. Egy új szúfaj - Xylosandrus germanus (Blandford, 1894) - megjelenése hazánkban (The first record of a new ambrosia beetle species - Xylosandrus germanus (Blandford, 1894) - in Hungary). Növényvédelem (Plant protection) 43, 8: 359-363

Löbl I., Smetana A. 2006. Catalogue of Palearctic Coleoptera. Vol. 3: Scarabaeoidea, Scirtoidea, Dascilloidea, Buprestoidea and Byrrhoidea: 690 str.

Mandelshtam M. 2001. Two new bark beetle (Scolytidae) pests in fauna of Russia. 12/10/2001

1Univerza v Ljubljani, Biotehniška fakulteta, Oddelek za gozdarstvo in obnovljive gozdne vire, Večna pot 83, 1000 Ljubljana; 2Zavod za gozdove Slovenije, OE Tolmin, Tumov drevored 17, 5220 Tolmin; ${ }^{3 Z a v o d}$ za gozdove Slovenije, OE Sežana, Partizanska cesta 49, 6210 Sežana *maja.jurc@bf.uni-lj.si 


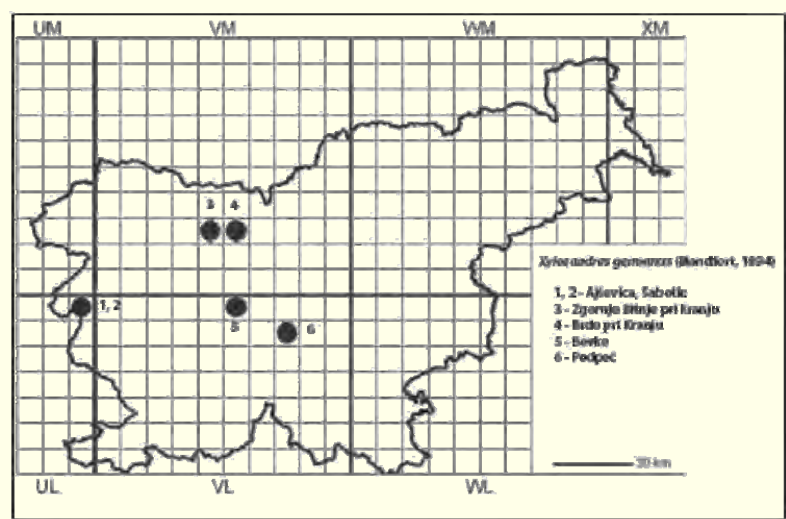

Slika 1. Najdišča Xylosandrus germanus v Sloveniji

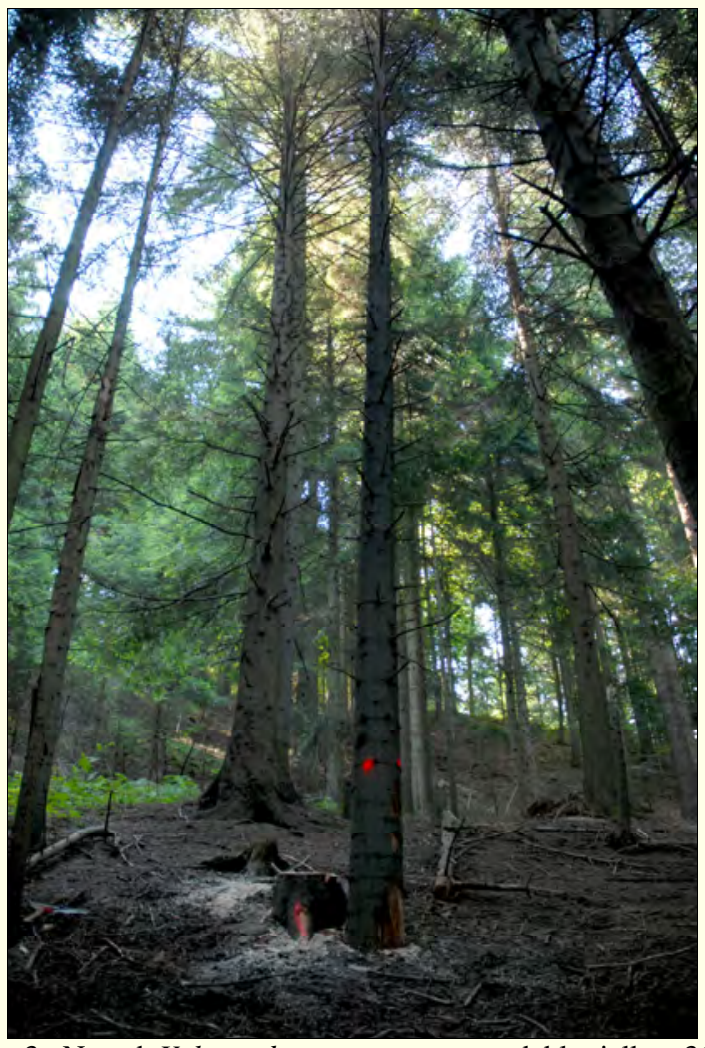

Slika 3. Napad Xylosandrus germanus na deblu jelke, 31. 5. 2009, lokacija Bevke, Mali plac

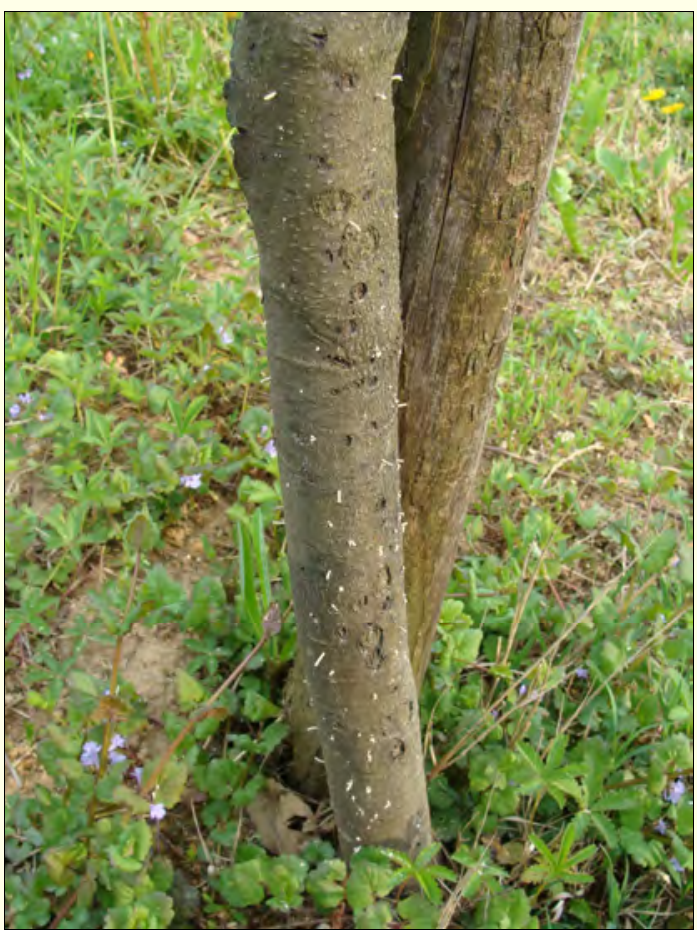

Slika 2. Napad Xylosandrus germanus na lokaciji Ajševica pri Novi Gorici maja 2010, kjer je povzročil sušenje drevja (foto. M. Reščič)

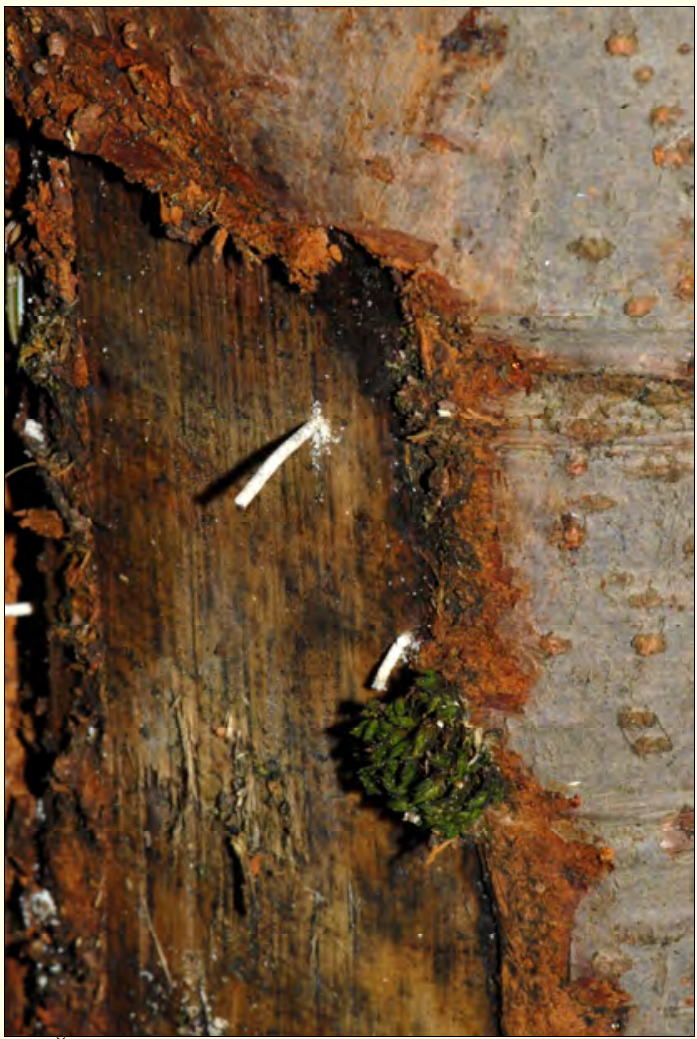

Slika 4. Črvina iz vhodne odprtine v obliki palčk je značilna za napad $X$. germanus 


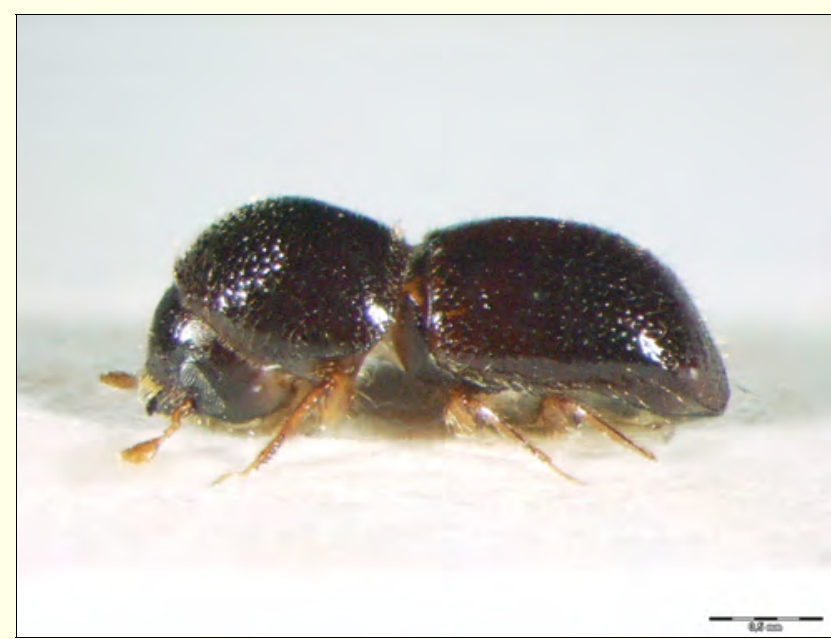

Slika 5. Xylosandrus germanus

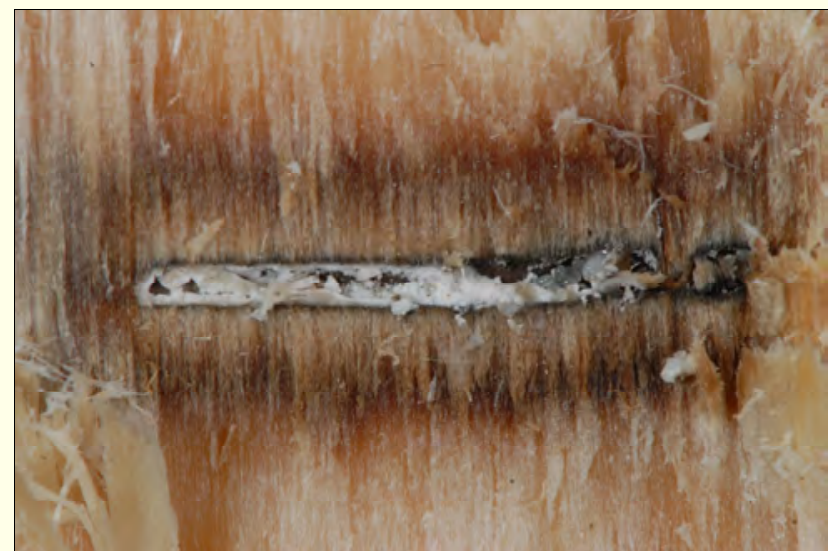

Slika 7. Xylosandrus germanus živi v povezavi z ambrozijskimi glivami, ki obarvajo in razgrajujejo les, v rovu so jajčeca (foto: D. Jurc)

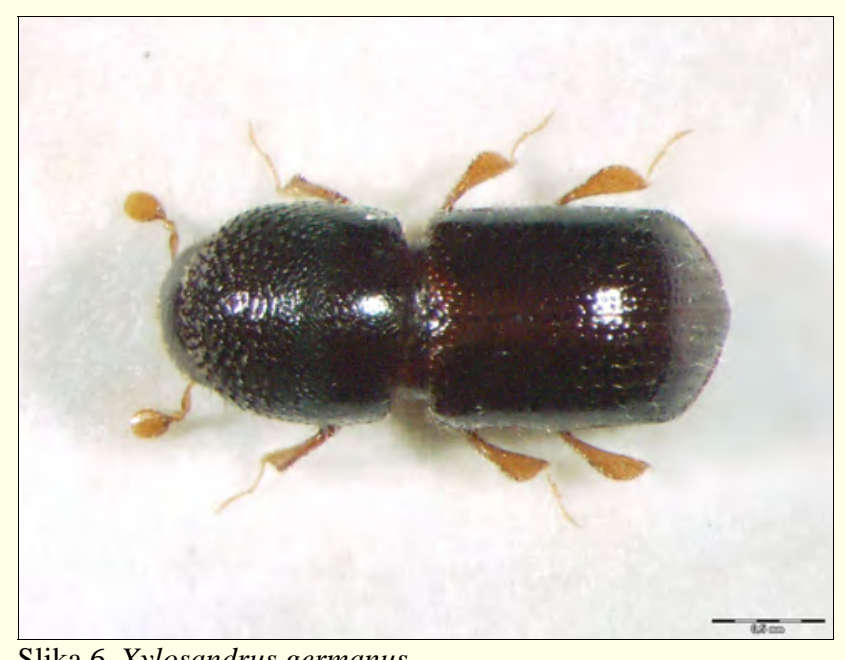

Slika 6. Xylosandrus germanus 